\title{
Trabalho interdisciplinar no contexto da prevenção do câncer do colo do útero
}

Thais Michele de Medeiros Riguete, Angélica Atala Lombelo Campos, Felipe Silva Neves, Ludmila Sathler Tavares, Alessanda Bonato Beghini Matri, Maria Teresa Bustamante Teixeira

\section{Resumo}

O trabalho interdisciplinar é estruturado a partir da articulação dos diferentes saberes, tendo como desafio o diálogo e interação de conhecimentos para a resolução de problemas. A interdisciplinaridade busca romper a hiperespecialização e a fragmentação dos saberes, caracterizando-se pela intensidade de trocas entre os especialistas. Enfatiza-se a relevância das ações interdisciplinares direcionadas ao controle do câncer cervical, sendo este considerado o quarto tipo de câncer mais prevalente na população feminina, que pode ser detectado precocemente por meio do exame citopatológico do colo do útero. Tal procedimento deve ser realizado em mulheres com vida sexual ativa, entre 25-59 anos de idade, ao menos uma vez por ano, ou, após dois exames anuais consecutivos negativos, a cada três anos. Descrever a experiência interdisciplinar da busca ativa de mulheres participantes de uma coorte. Trata-se de um relato de experiência a respeito de um projeto interdisciplinar para o rastreamento do câncer do colo do útero, no qual a população-alvo foi constituída por 449 mulheres, entre 20-59 anos de idade, que em 2011 participaram da primeira abordagem de uma coorte de base populacional realizada no município de Juiz de Fora - MG. Foi organizada uma força tarefa, incluindo as participações da equipe da Unidade de Atenção Primária à Saúde da respectiva região contemplada, bem como de profissionais e discentes das áreas de enfermagem, nutrição e medicina. Após sucessivas reuniões com todos os envolvidos, traçou-se um plano de ação, incluindo: os mapeamentos da população e do território adscrito; a busca ativa das mulheres através de visitas domiciliares; o contato telefônico, a divulgação do projeto no bairro e a oferta de exames em dias e horários atípicos (no período noturno e aos finais de semana). Após 8 meses, 297 mulheres foram avaliadas, 97 mudaram de bairro, 15 estavam gestantes ou haviam retirado o útero e 27 se recusaram a participar da pesquisa. Atualmente, restam 11 mulheres que já foram convidas e agendadas mais de três vezes, mas ainda não atenderam ao recrutamento. O projeto permitiu a troca de conhecimento e experiência entre os membros da equipe acerca dos fatores associados ao desenvolvimento do câncer do colo do útero, e maior entendimento sobre a doença e sua prevenção. A elaboração de novas estratégias de ação para promoverem uma melhor adesão ao programa de rastreio só foi possível diante do trabalho interdisciplinar. A experiência da integração curricular e da articulação ensino-serviço-comunidade foi desafiadora, mas possibilitou a construção de práticas inovadoras e exitosas. A interdisciplinaridade foi de suma importância para traçar caminhos alternativos que possibilitaram a ampliação da cobertura de exames.

Descritores: Trabalho interdisciplinar; Câncer do colo do útero; Rastreamento precoce. 